potential for growth, presumably as a result of metabolic disturbances during the pregnancy, and may therefore be termed "macrosomic."

Acker $e t a l$ ' reported that the incidence of shoulder dystocia in the deliveries of diabetic mothers was $50 \%, 23 \%$, and $9 \%$ for infants weighing $\geqslant 4500 \mathrm{~g}$, 4000-4499 g, and 3500-3999 g, respectively, compared with $23 \%, 10 \%$, and $2 \%$ for deliveries of non-diabetic mothers. Thus many more infants of diabetic mothers are too large for their maternal pelvis, even when their birthweight is apparently normal.

Control of diabetes in pregnancy should not be described as "good" or "bad" as it forms a continuous range and thus would not be expected to have an all or nothing effect on promoting fetal growth. A substantial percentage of infants of diabetic mothers with birth weights within the normal range will be affected by the metabolic disturbances in the uterus caused by diabetes. In a review of 225 infants of diabetic mothers Lemons et al reported that neonatal hypoglycaemia occurred not only in $36(47 \%)$ of the macrosomic infants, but also in $31(21 \%)$ of the infants with birth weights that were not large for gestational age. ${ }^{+}$The extent to which an infant will be affected by maternal diabetes, as measured by birth weight or neonatal hypoglycaemia, will vary, explaining why "good" control in the conventional sense may result in a big baby who becomes hypoglycaemic whereas "bad" control may result in a small baby who does not.

Our results suggest that all infants of diabetic mothers, irrespective of birth weight, are growth promoted to some degree by their mothers' disease, and thus every infant should be considered to be at risk from the biochemical and mechanical consequences of macrosomia.

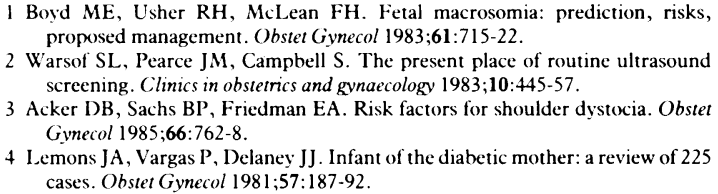

(Accepted 13 September 1988)

\title{
Magnesium free dialysis for uraemic pruritus
}

\author{
Andrew J Carmichael, Fred Dickinson, \\ Mary I McHugh, Anthony M Martin, Malcolm \\ Farrow
}

Department of Medicine,

Royal Infirmary,

Sunderland SR2 7JE

Andrew J Carmichael,

MRCP, medical registrar

Fred Dickinson, RGN, charge nurse

Mary I McHugh, FRCP, consultant nephrologist

Anthony M Martin, FRCP, consultant nephrologist

\section{Department of}

Mathematics and

Computer Studies,

Sunderland Polytechnic,

Sunderland SR2 3SD

Malcolm Farrow, PHD, senior

lecturer in statistics

Correspondence to: Dr A J

Carmichael, The Skin

Hospital, Edgbaston,

Birmingham B15 IPR.
The treatment of uraemic pruritus is difficult, as reflected by the variety of treatment that has been tried. ${ }^{1}$ Hypermagnesaemia is common in chronic renal failure $^{2}$ and has been shown to corrolate with itch. ${ }^{3}$ We investigated the effect on itch of lowering the serum magnesium concentration in a group of patients suffering from uraemic pruritus.

\section{Patients, methods, and results}

From an initial study of renal itch in patients undergoing long term haemodialysis 20 patients were identified as being severely affected by uraemic pruritus (itch score more than 200 a week). ${ }^{3}$ Three patients were excluded as they were on non-standard dialysis fluid, and the others continued to fulfil the previous entry requirements ${ }^{3}$ and were not taking drugs containing magnesium. The 17 patients included in the trial (one woman) were aged 25-69; had been undergoing maintenance haemodialysis for 4-79 months; received 9-14 hours of dialysis a week on Dylade D2 or Gambro AK10 machines, with Travenol ST12/11 dialysis membrane, and remained on the same machines and dialyser throughout the trial.

The patients were randomly allocated into two groups by a double blind technique. Group 1 (seven patients) remained on the standard dialysis fluid (McCarthy's QE136) with a magnesium concentration of $0.85 \mathrm{mmol} / \mathrm{l}$, while group 2 was changed to one free of magnesium (McCarthy's S597). In all other respects the composition of the dialysis fluid was identical. After two weeks the dialysis fluids of the two groups were swapped for a further fortnight. The serum magnesium concentration was measured before and after dialysis at entry and weekly throughout the trial. Serum parathyroid hormone concentration was measured at entry and at two and four weeks. The degree of itch was assessed by the patients completing visual analogue charts. ${ }^{3}$ All 17 patients completed the trial with no adverse symptoms noted.
On the standard dialysis fluid serum magnesium concentration was raised in most patients with mean concentrations before and after dialysis of 1.38 and $1.33 \mathrm{mmol} / \mathrm{l}$ (SEM $0.05 \mathrm{mmol} / \mathrm{l}$; normal range 0.70 $1.00 \mathrm{mmol} / \mathrm{l}$ ). The magnesium free dialysis fluid reduced the serum magnesium concentration to normal after a week, and after a fortnight the concentrations before and after dialysis were 0.87 and $0.62 \mathrm{mmol} / \mathrm{l}$ (SEM $0.06 \mathrm{mmol} / \mathrm{l}$ ). The reduction of the concentration was highly significant $(p<0.001$, analysis of variance). Lowering the serum magnesium concentration was associated with a significant increase $(p<0.01$, analysis of variance) in serum parathyroid hormone concentration (figure). Analysis of the itch score for weeks two and four (weeks one and three were omitted to diminish the carryover effect) showed no evidence of an effect from the treatment $(\mathrm{p}>0 \cdot 1$, Wilcoxon signed rank test).

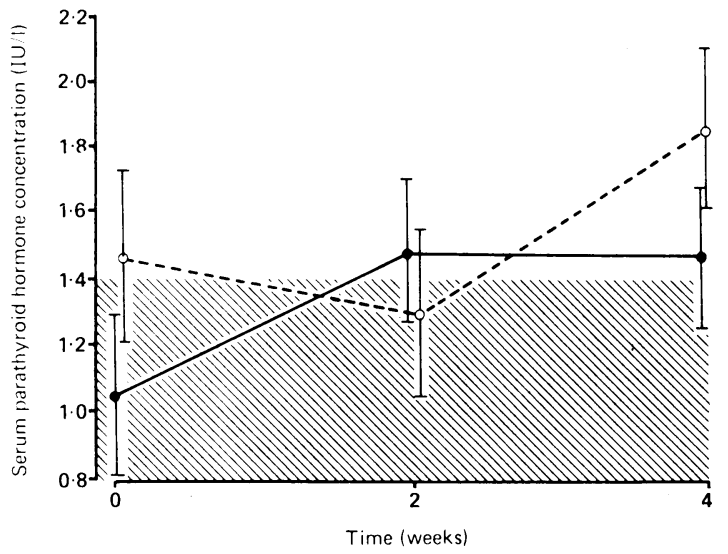

Change in serum parathyroid hormone concentration (SE) of group 1 $\left(\mathrm{O}-\mathrm{O}^{-}\right)$on magnesium free dialysis fluid for weeks three and four and group 2 (•—) on magnesium free dialysis fluid for weeks one and two. Shaded area shows normal range of serum parathyroid hormone concentration

\section{Comment}

Graf et al reported a case of recalcitrant uraemic pruritus responding within a week to a low magnesium dialysate ${ }^{4}$ a finding corroborated, but not quantified, by Nilsson et al using a similar dialysis fluid with a magnesium concentration of $0.2 \mathrm{mmol} / 1$. More recently we have shown a correlation between renal itch and serum magnesium concentration in patients 
receiving long term haemodialysis. ${ }^{3}$ In the present trial we showed that though a magnesium free dialysis fluid corrected the hypermagnesaemia, it failed to show a related improvement in the renal itch. In addition, the fall in the serum magnesium concentration was associated with an increased concentration of parathyroid hormone, as has been previously noted, ${ }^{5}$ with the potential of producing renal osteodystrophy in the long term.

The lack of response might have been due to the brevity of the magnesium free dialysis. A longer treatment period was avoided as we thought that the patients' reliability in completing the visual analogue charts was likely to deteriorate, and the hyper- magnesaemia was corrected within a week. Alternatively, the serum magnesium concentrations may, like phosphate, ${ }^{3}$ be acting as a marker for the adequacy of dialysis, and this is being investigated.

1 Anonymous. Uraemic pruritis [Editorial]. Br Med f 1980;281:1025

2 Coburn JW, Popovtzer MM, Massry SG, Kluman CR. The physiochemical state and renal handling of divalent ions in chronic renal failure. Arch Intern Med 1969;124:302-11.

3 Carmichael AJ, McHugh MM, Martin AM, Farrow M. Serological markers of renal itch in patients receiving long term haemodialysis. $\mathrm{Br}$ Med $\mathrm{f}$ 1988;296:1575.

4 Graf H, Kovarik J, Stummvoll HK, Wolf A. Disappearance of uraemic pruritis after lowering dialysate magnesium concentration. $\mathrm{Br} M e d$ f 1979 ;ii: 1478-9.

5 Nilsson P, Johansson SG, Danielson BG. Magnesium studies in haemodialysis patients before and after treatment with low dialysate magnesium. Nephron 1984;37:25-9.

(Accepted 8 September 1988)

\section{Prostitute women and public health}

\section{S Day, H Ward, J R W Harris}

\section{Department of \\ Anthropology, London \\ School of Economics and \\ Political Science, London \\ WC2 \\ S Day, MA, research officer}

Academic Department of

Community Medicine,

St Mary's Hospital,

London W2

$\mathrm{H}$ Ward, $\mathrm{MB}$, research fellow

in epidemiology

Praed Street Clinic,

St Mary's Hospital,

London W2

J R W Harris, FRCP, senior consultant in genitourinary

medicine

Correspondence to: $\mathrm{Ms} \mathrm{S}$

Day, Praed Street Clinic,

St Mary's Hospital, London

W2 $1 \mathrm{NY}$. tutes.

\section{Patients and results}

Prostitute women have been allotted a key role in models of heterosexual transmission of human immunodeficiency virus (HIV). Prostitutes are assumed to be especially exposed to infection with HIV because they have a greater than average number of sexual partners, and infected prostitutes may then play an important part in spreading the virus. Debates on public health initiatives reflect this concern with recommendations for registering and screening prosti-

Though some findings from Africa confirm the importance of prostitutes in the heterosexual transmission of HIV, as in Nairobi, ${ }^{2}$ sexual activity alone has not been described as the principal risk elsewhere in the world. The most important risk factor for prostitutes in the West is sharing needles and syringes for drugs. ${ }^{3}$ We studied a cohort of prostitute women in London to assess their risks of infection with HIV.

Ninety one women were followed up for a median of seven months at the Praed Street Clinic over 17 months to December 1987. Questions about use of condoms showed that the women practised safer sex with clients than with private sexual partners (boyfriends) at their first visit and that this pattern was maintained over time (table). Four of 34 women attending the clinic in the last three months of 1987 reported inconsistent use of condoms with clients. This partly depended on the type of client: one sexual encounter with a new client was unprotected compared with 28 encounters with regular clients, who pay the same woman repeatedly for sex.

Changes in use of condoms in 91 women attending the Praed Street Clinic to December 1987

\begin{tabular}{|c|c|c|c|}
\hline \multirow[b]{2}{*}{ Type of sexual intercourse } & \multirow[b]{2}{*}{$\begin{array}{l}\text { No reporting } \\
\text { this type }\end{array}$} & \multicolumn{2}{|c|}{ No always using condoms } \\
\hline & & $\begin{array}{l}\text { At first visit } \\
\text { to clinic }\end{array}$ & $\begin{array}{l}\text { At last visit } \\
\text { to clinic }\end{array}$ \\
\hline Vaginal with clients & 91 & 54 & $68^{\star}$ \\
\hline Oral with clients & $57 \dagger$ & 22 & $28^{\star}$ \\
\hline Anal with clients & $3 \ddagger$ & 2 & 1 \\
\hline Vaginal with boyfriends & $71^{\circ}$ & 4 & 8 \\
\hline
\end{tabular}

A total of 187 prostitutes were tested with their consent for HIV-1. Three (1.6\%) were positive for antibodies to HIV; two had shared needles in the past, and one had probably been infected by her boyfriend, who was positive for the virus. Infection in this woman, who did not use needles, may have been due to the general practice of unsafe sex at home. Information obtained from prostitutes in the cohort during interviews suggested that half of their boyfriends had other sexual partners, but possible risks associated with these men were unclear.

\section{Comment}

We did not find any evidence that prostitutes' fairly high rates of change of client were placing them at special risk of infection with HIV. Their safety at work depends partly on the extent to which condoms protect against infection with $\mathrm{HIV}^{4}$ and also on the prevalence of HIV in the population of clients. Women in the cohort who used condoms all the time had notably fewer infections with common genital pathogens than inconsistent users ( $\mathrm{H}$ Ward, unpublished observations). No client of a prostitute in London has been found to be positive for antibodies to HIV at the clinic (data not shown).

The current pattern of infection with HIV and the use of condoms in our cohort carry an important methodological implication. Risks of infection in prostitute women are not associated only with a high rate of change of clients. Risks associated with shared injecting equipment are well established, ${ }^{3}$ and risks associated with private sexual relationships are becoming evident. ${ }^{s}$ Though public health measures designed to increase use of condoms among clients and prostitutes may yield good results, introducing the use of condoms into all sexual relationships is more difficult. Regular clients and boyfriends, who have qualitatively different relationships with the women, are often unwilling to use condoms.

Enumerating stigmatised populations such as prostitutes is not possible, and therefore findings from our study can be generalised only with caution. A trend towards universal use of condoms with new clients and increasing use with regular clients and boyfriends is, however, encouraging.

1 Centres for Disease Control. Antibody to human immunodeficiency virus in female prostitutes. $M M W R$ 1987;36:157-61.

Piot P, Plummer FA, Rey MA, et al. Retrospective seroepidemiology of HIV infection in Nairobi populations. F Infect Dis 1987;155:1108-12.

Des Jarlais D, Friedman S. HIV infection among intravenous drug users. AIDS 1987;1:67-76.

4 Van de Perre P, Jacobs D, Sprecher-Goldberger S. The latex condom, an efficient barrier against sexual transmission of AIDS-related viruses. AIDS 1987;1:49-52.

5 Rosenberg MJ, Weiner JM. Prostitutes and AIDS: a health department priority? Am f Public Health 1988;78:418-23.

(Accepted 3 October 1988) 